\title{
Reactive Cerium(IV) Oxide Powders by the Homogeneous Precipitation Method
}

\author{
Pei-Lin Chen ${ }^{\star}$ and I-Wei Chen ${ }^{\star}$
}

Department of Materials Science and Engineering, University of Michigan, Ann Arbor, Michigan 48109-2136

$\mathrm{CeO}_{2}$ powders have been prepared by aging a cerium(III) nitrate solution in the presence of hexamethylenetetramine. Oxidation of $\mathrm{Ce}^{3+}$ occurs in the precipitate and the wet precipitate is identified as crystallized $\mathrm{CeO}_{2}$ before any heat treatment. The cold-pressed powders can be sintered to full density at temperatures as low as $1250^{\circ} \mathrm{C}$ in just $6 \mathrm{~min}$. Moreover, the sinterability of the powders is insensitive to the calcination temperatures, particle size, or green density. The powders calcined at $850^{\circ} \mathrm{C}$ with a crystallite size of $600 \AA$ have a sinterability as good as the powders calcined at $450^{\circ} \mathrm{C}$ with a crystallite size of $145 \AA$. The mechanisms for direct $\mathrm{CeO}_{2}$ precipitation and its relation to the excellent sinterability are discussed.

\section{Introduction}

$\mathbf{H}$ IGHLY refractory oxides such as $\mathrm{UO}_{2}, \mathrm{ThO}_{2}, \mathrm{CeO}_{2}, \mathrm{Y}_{2} \mathrm{O}_{3}$, and $\mathrm{R}_{2} \mathrm{O}_{3}(\mathrm{R}=$ trivalent rare-earth elements) are difficult to sinter to high density below $1500^{\circ} \mathrm{C}$ in air without sintering additives. Typically, to obtain fully dense bodies, these ceramics are fired above $1800^{\circ} \mathrm{C}$ and in a special atmosphere such as hydrogen. Sinterability can be improved by using better powders. Research on $\mathrm{Y}_{2} \mathrm{O}_{3}{ }^{1-3}$ has shown that monosized spherical powders of $0.2-\mu \mathrm{m}$ particle size can be sintered to $99.9 \%$ of theoretical density at $1700^{\circ} \mathrm{C}$. This compares with powders of irregular shapes and larger sizes which reached only $98 \%$ in dry $\mathrm{H}_{2}$ at $2100^{\circ} \mathrm{C}$. Similar success in improving sinterability through better powder processing for other refractory oxides in the above family, however, has not been reported. In this paper, we describe a precipitation method for producing highly reactive $\mathrm{CeO}_{2}$ powders sinterable below $1300^{\circ} \mathrm{C}$.

In a typical precipitation procedure, oxide powders or their precursors are obtained by adding a ligand, say ammonia, directly to a solution containing metal cations. An insoluble salt is precipitated once its solubility limit is exceeded. This procedure has little control over the precipitate shape and size because of the rapid change of solution concentration and the localized, discontinuous nature of ligand introduction and reaction. A better control can be rendered if the ligand, and hence precipitates, are generated simultaneously and uniformly throughout the solution. The latter process, when practicable, is termed a homogeneous precipitation method. Techniques for obtaining homogeneous precipitates have been reported as early as 1937 by Wiliard and Tang in forming aluminum sulfate. $^{4}$

A common key feature of homogeneous precipitate methods is the controlled release of the reaction-participating ligands by another source chemical in the solution. Urea, which can

D. Shanefield-contributing editor slowly decompose to yield ammonia and $\mathrm{HNCO}$, in situ, may be used as the ligand source for ammonia as demonstrated by the original work of Wiliard and Tang. More recently, Sordelet and Akinc ${ }^{5}$ prepared spherical, monosized yttrium oxide precursor particles using urea and an yttrium salt. Aiken and coworkers $^{6}$ also used the same method to prepare an $\mathrm{Y}(\mathrm{III}) / \mathrm{Ce}$ (III) mixed compound with spherical morphology. (Roman numerals are used here to designate valence states.) Similarly, Matijevic and $\mathrm{Hsu}^{7}$ showed that many trivalent lanthanide ions $\left(\mathrm{Sm}^{3+}, \mathrm{Eu}^{3+}, \mathrm{Gd}^{3+}\right.$, and $\left.\mathrm{Tb}^{3+}\right)$ precipitated in a urea solution as amorphous hydroxyl carbonate compounds of the spherical shape with a narrow size distribution.

Interestingly, the above urea-based method seemed inappropriate for precipitating pure $\mathrm{Ce}$ (III) compounds. The crystalline compound of $\mathrm{Ce}_{2} \mathrm{O}\left(\mathrm{CO}_{3}\right)_{2} \cdot \mathrm{H}_{2} \mathrm{O}$ obtained by Matijevic and $\mathrm{Hsu}^{7}$ were not in spherical form despite attempts over a wide variety of reaction conditions. On the other hand, spherical cerium(IV) oxide sols have been prepared by $\mathrm{Hsu}$ et al ${ }^{8}$ using hydrolytic deprotonation of $\mathrm{Ce}$ (IV) ions in the presence of dilute sulfuric acid. Unfortunately, the method requires a relatively low cation concentration $\left(5 \times 10^{-4} \mathrm{M}\right)$ and thus is not practical for powder production. It should be noted that in all of the cases quoted above, the sinterability of ceria powders was not reported.

An alternative to urea as an ammonia source can, in principle, be found in other compounds. For example, hexamethylenetetramine (HMT) can hydrolyze slowly to yield ammonia and formaldehyde. ${ }^{9}{ }^{10}$ In this case, the rate of homogeneous precipitation is controlled by hexamethylenetetramine hydrolysis. Such a method has been used for preparing $\mathrm{ZnO} .^{11.13} \mathrm{By}$ aging a nitric aqueous solution at elevated temperatures in the presence of HMT, ultrafine $\mathrm{ZnO}$ particles with a specific surface area of $9 \mathrm{~m}^{2} / \mathrm{g}$ were synthesized. ${ }^{13}$ The powders so obtained were usually not spherical in shape and their sinterability was not known.

The goal of this research is to prepare $\mathrm{CeO}_{2}$ powders of high sinterability. Pure $\mathrm{CeO}_{2}$ will undergo reduction at high temperature which necessitates a low sintering temperature and an oxidizing environment. High-quality, reactive powders are thus essential for obtaining high-density $\mathrm{CeO}_{2}$ bodies. We have successfully prepared $\mathrm{CeO}_{2}$ powders directly from cerium(III) nitrate and hexamethylenetetramine (Ce-HMT method) by controlling the reaction conditions. These powders can be easily compacted by conventional die pressing and wet-bag processes, and the sinterability is found to be insensitive to the calcination temperatures. Fully dense bodies have been obtained after firing in air at as low a temperature as $1250^{\circ} \mathrm{C}$ for only $6 \mathrm{~min}$. In the following sections we describe the method of powder preparation, the powder characteristics, and the sintering behavior. For comparison, corresponding $\mathrm{CeO}_{2}$ powders prepared by the direct ammonia method $\left(\mathrm{Ce}-\mathrm{NH}_{4} \mathrm{OH}\right.$ method) and by the urea method (Ce-urea method) are also reported.

Manuscript No. 195685. Received May 18, 1992; approved November 6, 1992. Presented at the 94th Annual Meeting of the American Ceramic Society, Minne-
apolis, MN, April 15, 1992 (Basic Science Division, Paper No. 150-B-92).

Supported by the U.S. Department of Energy under Grant No. DE-FG02-87ER45302.

* Member, American Ceramic Socicty.

\section{Experimental Procedure}

Cerium nitrate $\left(\mathrm{Ce}\left(\mathrm{NO}_{3}\right)_{3}\right.$, Alfa), hexamethylenetetramine $\left(\left(\mathrm{CH}_{2}\right)_{6} \mathrm{~N}_{4}\right.$, Lancaster $)$, urea $\left(\left(\mathrm{NH}_{2}\right)_{2} \mathrm{CO}\right.$, Fisher $)$, and ammonia $\left(\mathrm{NH}_{4} \mathrm{OH}\right.$, Mallinckrodt) were used as starting materials. When 
needed, dilute nitric acid or ammonia was used to adjust the $\mathrm{pH}$ value. Stock solutions were prepared by dissolving cerium nitrate in doubly distilled water and filtering through a porous membrane (pore size $=0.45 \mathrm{~mm}$ ). Acid, base, and organic chemicals were used without further purification.

In the Ce-HMT method, a proper amount of solution was diluted into desired concentrations $(0.0375 M$ for the $\mathrm{Ce}$ (III) salt), and $0.5 M$ hexamethylenetetramine was dissolved in the dilute solution. The mixed solution was first aged at room temperature overnight, then heated to $70 \pm 1{ }^{\circ} \mathrm{C}$ for $1 \mathrm{~h}$ to effect precipitation. The resulting dispersions were filtered through a $0.2-\mu \mathrm{m}$ membrane, and the recovered precipitates were washed with isopropyl alcohol. The washed precipitates were dried overnight in an oven at $85^{\circ} \mathrm{C}$ in air, then calcined at various temperatures.

In the $\mathrm{Ce}$-urea method, $0.5 M$ urea was dissolved in a $0.008 M$ cerium nitrate solution. The solution was then heated to $85 \pm \mathrm{I}^{\circ} \mathrm{C}$ for $1 \mathrm{~h}$ to effect precipitation. The recovered precipitates were washed with acetone, oven dried, and calcined. (The above method is similar to that reported in the literature. ${ }^{7}$ )

In the $\mathrm{Ce}-\mathrm{NH}_{4} \mathrm{OH}$ method, ammonia was added directly to a $0.0375 M$ cerium nitrate solution until the $\mathrm{pH}$ value was 10 to effect precipitation at room temperature. The precipitates were washed with water and isopropyl alcohol, vacuum dried at room temperature, and calcined.

To evaluate the sinterability of these powders, cylindrical pellets were prepared by uniaxial dry pressing, followed by isostatic pressing. They were sintered in air at $1320^{\circ} \mathrm{C}$ or lower temperatures for $6 \mathrm{~min}$ using a constant heating rate of $10^{\circ} \mathrm{C} / \mathrm{min}$. In a separate experiment, sintering shrinkage from room temperature to $1450^{\circ} \mathrm{C}$ was monitored using a dilatometer operated in air at a constant heating rate of $10^{\circ} \mathrm{C} / \mathrm{min}$.

The phase identification was performed by the X-ray diffraction (XRD) method using $\mathrm{Cu} K \alpha$ radiation. When needed, coarse-grained metal Ni powders were used as a standard, and the crystallite size was estimated by line broadening analysis taking into account the instrument broadening with reference to the Ni standard. Precipitate morphology was examined by transmission electron microscopy (TEM) and scanning electron microscopy (SEM). The specific surface area of the powders was measured by BET. Microstructural examination of the interior of the sintered specimens was performed on polished and thermally etched surfaces. The tapped density and the green density of the compacts were calculated from the dimensions of the samples and their weight, and the sintered density was determined by the water displacement method.

\section{Results}

\section{(1) Chemistry and Powder Characteristics-Ce-HMT Method}

The yield for the Ce-HMT process was between $70 \%$ and $75 \%$. During the process, we observed systematic changes in color and $\mathrm{pH}$ value of the solution. After hexamethylenetetramine was dissolved in the cerium nitrate solution, the originally clear solution gradually became lightly translucent. The color variance during room-temperature aging was very slow. For example, after overnight aging we observed a lightly opaque solution of pale purple. Subsequently, the solution turned into pinkish-purple while being heated up. The wet recovered precipitate appeared purple but the oven-dried precipitate was khaki yellow. Finally, the calcined powders were lemon yellow.

Meanwhile, the $\mathrm{pH}$ value of the solution during processing was changing as schematically shown in Fig. 1. Starting with distilled water having a $\mathrm{pH}$ value of 5.5 , the dilute cerium nitrate solution had a $\mathrm{pH}$ value of about 4.4 . It changed to 6.9 after the dissolution of hexamethylenetetramine. During roomtemperature aging, the $\mathrm{pH}$ value of the solution decreased

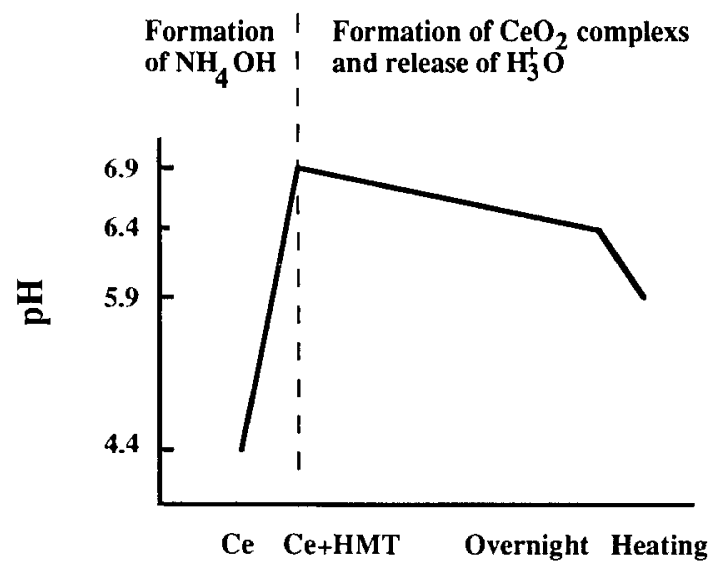

Fig. 1. Change of $\mathrm{pH}$ value during powder processing.

slowly (from 6.9 to 6.4), and the decreasing rate became faster during subsequent heating (from 6.4 to 5.9 in $1 \mathrm{~h}$ ).

Figure 2 shows XRD patterns of powders produced by the $\mathrm{Ce}-\mathrm{HMT}$ method with various heat treatments. Also included in Fig. 2(a) is the XRD for the $\mathrm{Ce}-\mathrm{NH}_{4} \mathrm{OH}$ method, as will be discussed later. It is noteworthy that the wet precipitate (see Fig. 2(b)) already displayed all of the major reflections of $\mathrm{CeO}_{2}$ with a fluorite structure. After drying, heating, and calcination, the characteristic peaks of $\mathrm{CeO}_{2}$ became sharper, and the higher the heat treatment temperature, the sharper the peaks.

We have investigated the evolution of the crystallite sizes during heat treatment. Figure 3 summarizes the data obtained from line-broadening analysis of the 111 peak in XRD as a function of heat treatment temperatures. As can be seen, the crystallite size grows slowly if the calcination temperature is below $450^{\circ} \mathrm{C}$. At this point, the average crystallite size is 145 $\AA$. However, calcination at $850^{\circ} \mathrm{C}$ increased the average crystallite size by about fourfold to $600 \AA$.

This coarsening trend in crystallite size is confirmed by other measurements. Figures 4(a) and (b) compare powders after calcination as viewed by TEM. The micrograph in Fig. 4(a) is for the powders calcined at $450^{\circ} \mathrm{C}$. It reveals a very fine particle size, $\approx 65 \AA$, although some variation is clearly present. After calcination at $850^{\circ} \mathrm{C}$, the particle size coarsens to $450 \AA$. Additionally, the BET specific surface area of the powders after $450^{\circ} \mathrm{C}$ calcination was $53 \mathrm{~m}^{2} / \mathrm{g}$ and after $850^{\circ} \mathrm{C}$ calcination 14 $\mathrm{m}^{2} / \mathrm{g}$. Assuming particles are closed spheres with smooth surfaces and using the $\mathrm{CeO}_{2}$ density of $7.132 \mathrm{~g} / \mathrm{mL}$, the calculated average diameters of the spheres are 79 and $303 \AA$, respectively.

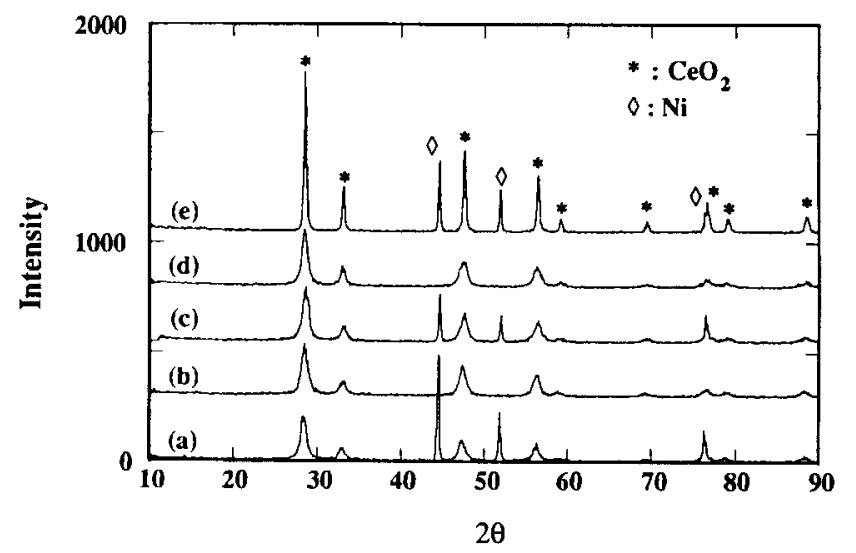

Fig. 2. X-ray diffraction patterns for Ce powders: (a) $\mathrm{Ce}-\mathrm{NH}_{4} \mathrm{OH}$ vacuum dried at room temperature; (b) Ce-HMT wet precipitate; (c) as (b), oven dried at $85^{\circ} \mathrm{C}$; (d) as (b), calcined at $200^{\circ} \mathrm{C}$ for $1.5 \mathrm{~h}$; (e) as (b), calcined at $850^{\circ} \mathrm{C}$ for $1.5 \mathrm{~h}$. 


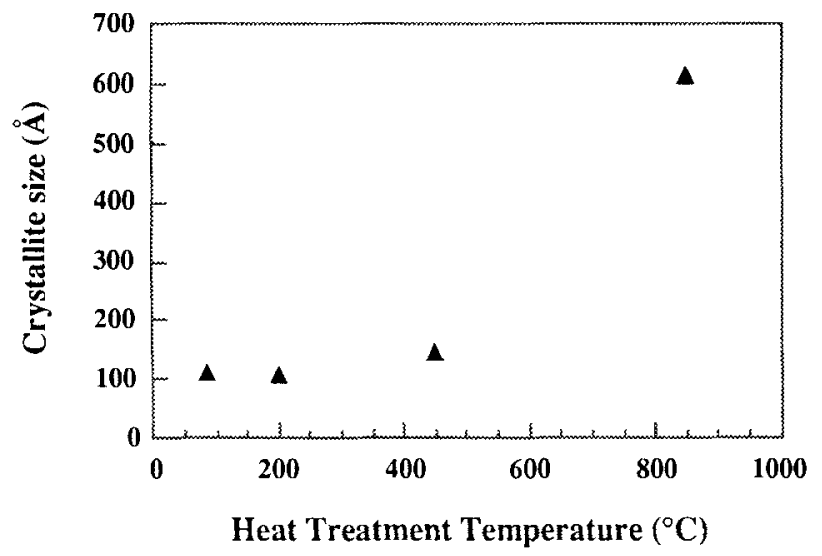

Fig. 3. Average crystallite sizes determined from 111 reflection $\left(d_{111}\right)$ versus heat treatment temperatures.
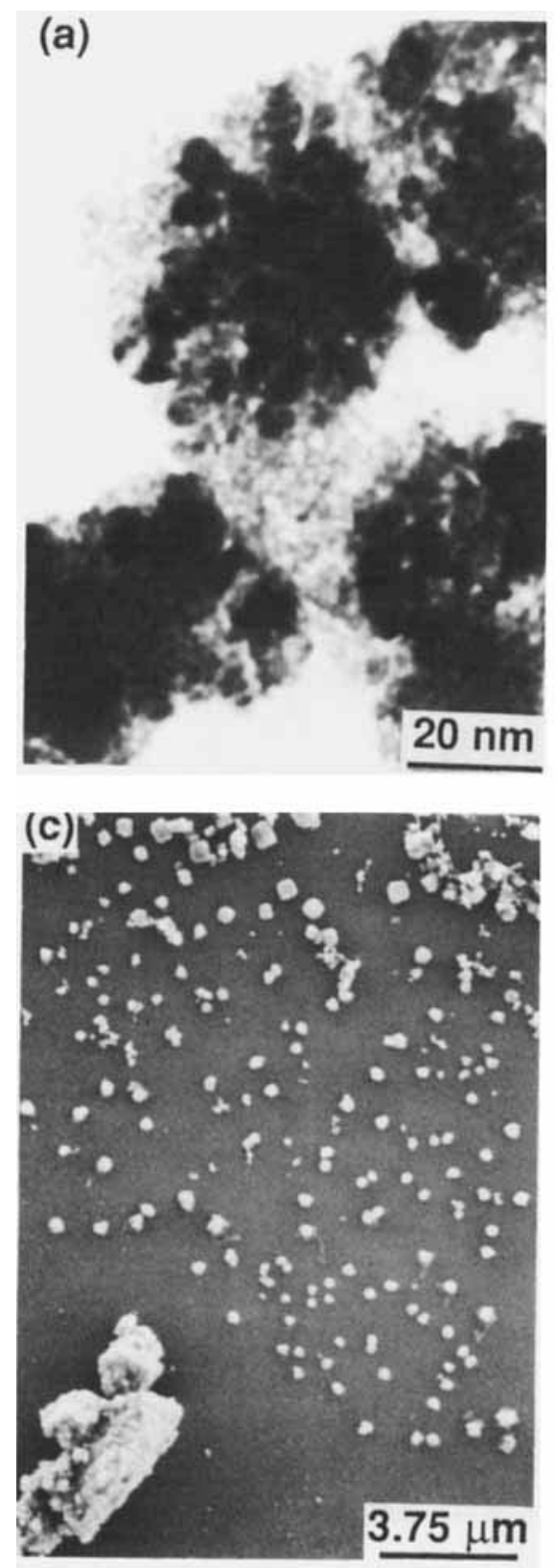

Summarizing these data, it is obvious that the powders obtained from the Ce-HMT method are initially very fine and remain so after calcination at $450^{\circ} \mathrm{C}$. A higher calcination temperature of $850^{\circ} \mathrm{C}$ coarsens the powder considerably although the crystallite size is still below $600 \AA$. With such a fine size, the powders appear very loose with a tapped density of 0.37 $\mathrm{g} / \mathrm{mL}$ after $450^{\circ} \mathrm{C}$ calcination and $1.0 \mathrm{~g} / \mathrm{mL}$ after $850^{\circ} \mathrm{C}$ calcination

\section{(2) Chemistry and Powder Characteristics- $-\mathrm{Ce}-\mathrm{NH}_{4} \mathrm{OH}$ and $\mathrm{Ce}$-Urea Methods}

The XRD data shown in Fig. 2(a) identify the precipitate of the $\mathrm{Ce}-\mathrm{NH}_{4} \mathrm{OH}$ method as $\mathrm{CeO}_{2}$ of a very fine crystallite size. The morphology of this powder after $450^{\circ} \mathrm{C}$ calcination is revealed by Fig. 4(c) and seems mostly equiaxed. However, the size distribution is extremely broad with the smaller particles of $0.1 \mu \mathrm{m}$ appearing in groups of two or three against some agglomerates as large as $7.0 \mu \mathrm{m}$. Its tapped density is $1.8 \mathrm{~g} / \mathrm{mL}$ after $450^{\circ} \mathrm{C}$ calcination, which is much higher than that of the Ce-HMT powders.
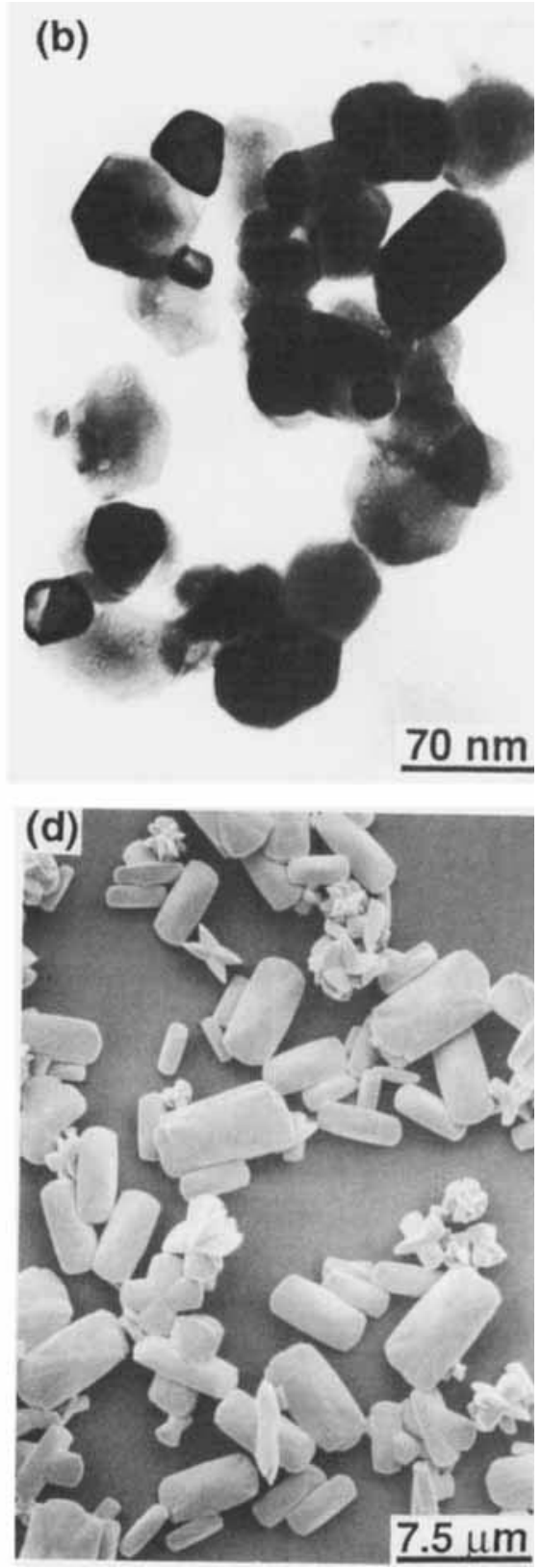

Fig. 4. TEM micrographs of powders prepared by $\mathrm{Ce}-\mathrm{HMT}$ method calcined at $450^{\circ} \mathrm{C}$ (a) and $850^{\circ} \mathrm{C}$ (b) for $1.5 \mathrm{~h}$. Compare SEM micrographs of powders by $\mathrm{Ce}-\mathrm{NH}_{4} \mathrm{OH}$ method (c) and Ce-urea method (d), both calcined at $450^{\circ} \mathrm{C}$ for $1.5 \mathrm{~h}$. 
The precipitate from the $\mathrm{Ce}$-urea method, dried at $85^{\circ} \mathrm{C}$, was identified as $\mathrm{Ce}_{2} \mathrm{O}\left(\mathrm{CO}_{3}\right)_{2}$ by XRD. After calcination at $450^{\circ} \mathrm{C}$ for $1.5 \mathrm{~h}, \mathrm{Ce}_{2} \mathrm{O}\left(\mathrm{CO}_{3}\right)_{2}$ was converted to $\mathrm{CeO}_{2}$. The morphology of the powder is illustrated by the SEM micrograph in Fig. 4(d). Both short rods and flower or starlike flakes are clearly visible. The average dimensions of the particles are much larger than those of the other two methods.

\section{(3) Sinterability}

The sinterability of powders from the three preparation methods is compared in Fig. 5. All powders were calcined at $450^{\circ} \mathrm{C}$ for $1.5 \mathrm{~h}$ before sintering. As illustrated in Fig. 5(a), the powders synthesized by the Ce-HMT method have reached full density at $1250^{\circ} \mathrm{C}$ in just $6 \mathrm{~min}$. At a higher sintering temperature, $1320^{\circ} \mathrm{C}$, full density was again achieved but the grain size was coarser, as is evident from Fig. 5(b). At the latter temperature, the powders from the $\mathrm{Ce}-\mathrm{NH}_{4} \mathrm{OH}$ method reached a relative density of $92 \%$ with a microstructure consisting of porous regions embedded in a much denser background, as shown in Fig. 5(c). The powder of the Ce-urea method behaved even worse; the sintered body contained continuous porous regions with a relative density of only $78 \%$

Experiments were also carried out to investigate the effect of calcination temperature on the sinterability of the Ce-HMT
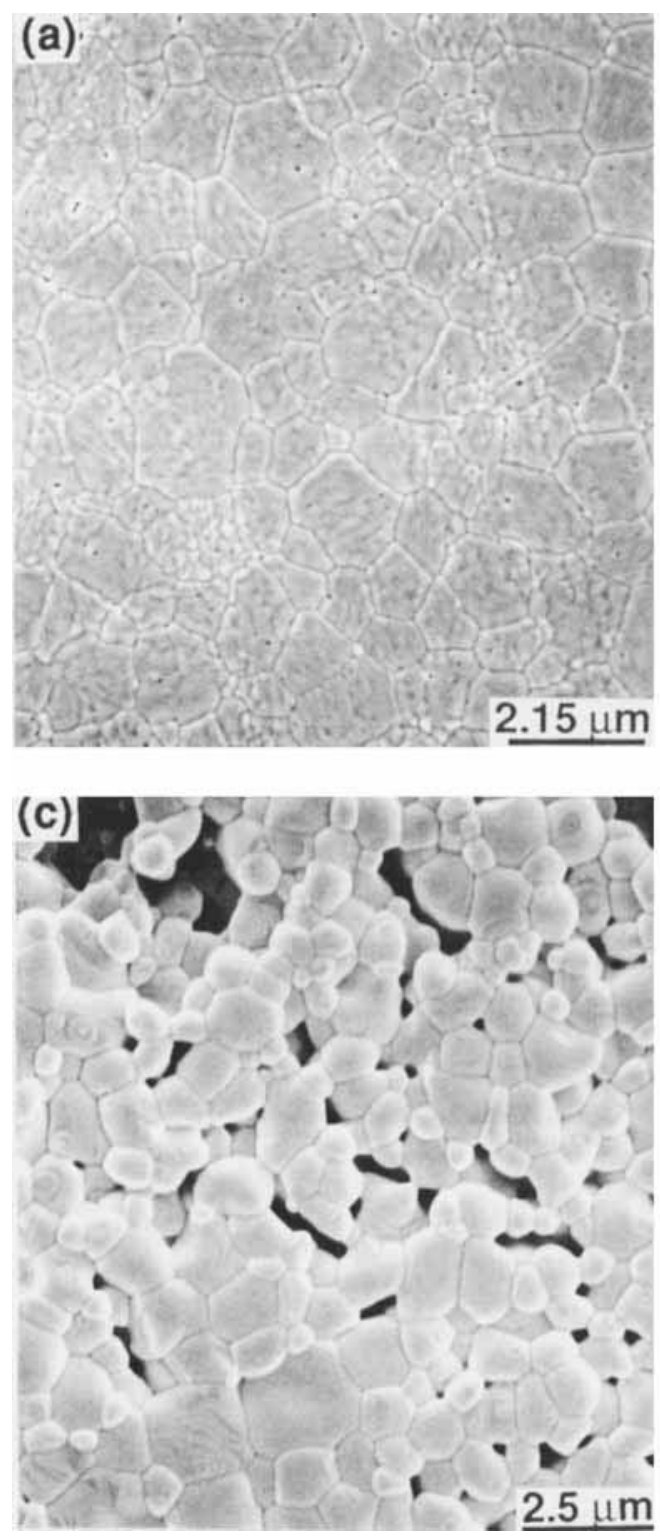

powders. As evident from Table I, full density at $1320^{\circ} \mathrm{C}$ has been reached by all of the Ce-HMT powders despite their different green density, from 2.9 to $3.7 \mathrm{~g} / \mathrm{mL}$. The microstructures of three sintered bodies using differently heat-treated powders are shown in Fig. 6. It is clear that even though the powders calcined at $850^{\circ} \mathrm{C}$ are coarser, their compacts are fully dense. Compared to the other two bodies, made of much finer starting powders, the grain size distribution using $850^{\circ} \mathrm{C}$ calcined powder is apparently more uniform.

Dilatometer data shown in Fig. 7 provide further information on the sintering behavior of these highly reactive powders. Not

Table I. Green Density and Properties of Sintered Bodies $\left(1320^{\circ} \mathrm{C}\right.$ for $\left.6 \mathrm{~min}\right)$ Using Powders Prepared by Ce-HMT Method Calcined at Different Temperatures

\begin{tabular}{cccc}
\hline $\begin{array}{c}\text { Calcination } \\
\text { temperature } \\
\left({ }^{\circ} \mathrm{C}\right)\end{array}$ & $\begin{array}{c}\text { Green } \\
\text { density } \\
(\mathrm{g} / \mathrm{mL})\end{array}$ & $\begin{array}{c}\text { Grain } \\
\text { size } \\
(\mu \mathrm{m})\end{array}$ & $\begin{array}{c}\text { Sintered } \\
\text { density } \\
(\mathrm{g} / \mathrm{mL})\end{array}$ \\
\hline 200 & 2.9 & 1.45 & 7.12 \\
450 & 2.9 & 1.45 & 7.13 \\
850 & 3.7 & 1.46 & 7.13 \\
\hline
\end{tabular}
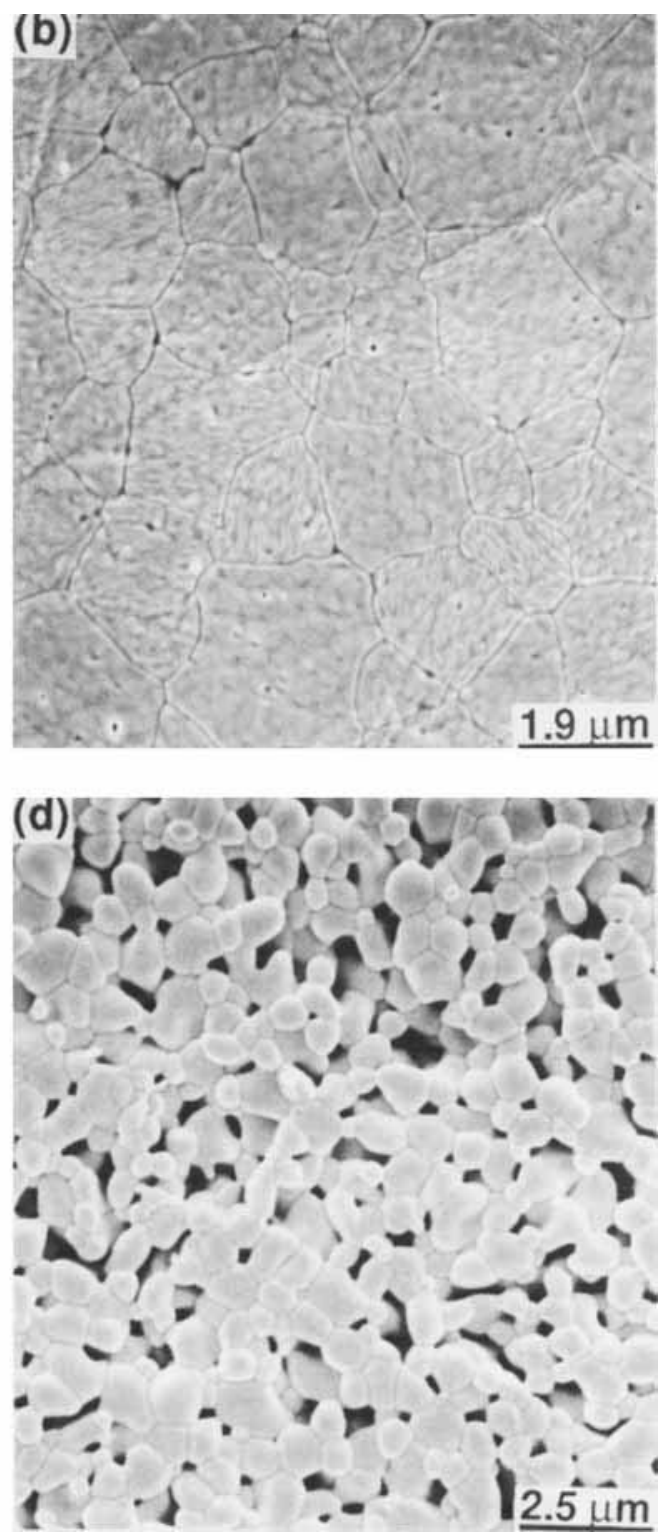

Fig. 5. Microstructures of sintered specimens from Ce-HMT method sintered for 6 min at (a) $1250^{\circ}$ and (b) $1320^{\circ} \mathrm{C}$. Compare specimens from powders of (c) the $\mathrm{Ce}-\mathrm{NH}_{4} \mathrm{OH}$ method sintered at $1320^{\circ} \mathrm{C}$ for 6 min and (d) the $\mathrm{Ce}$-urea method sintered at $1320^{\circ} \mathrm{C}$ for $6 \mathrm{~min}$. 

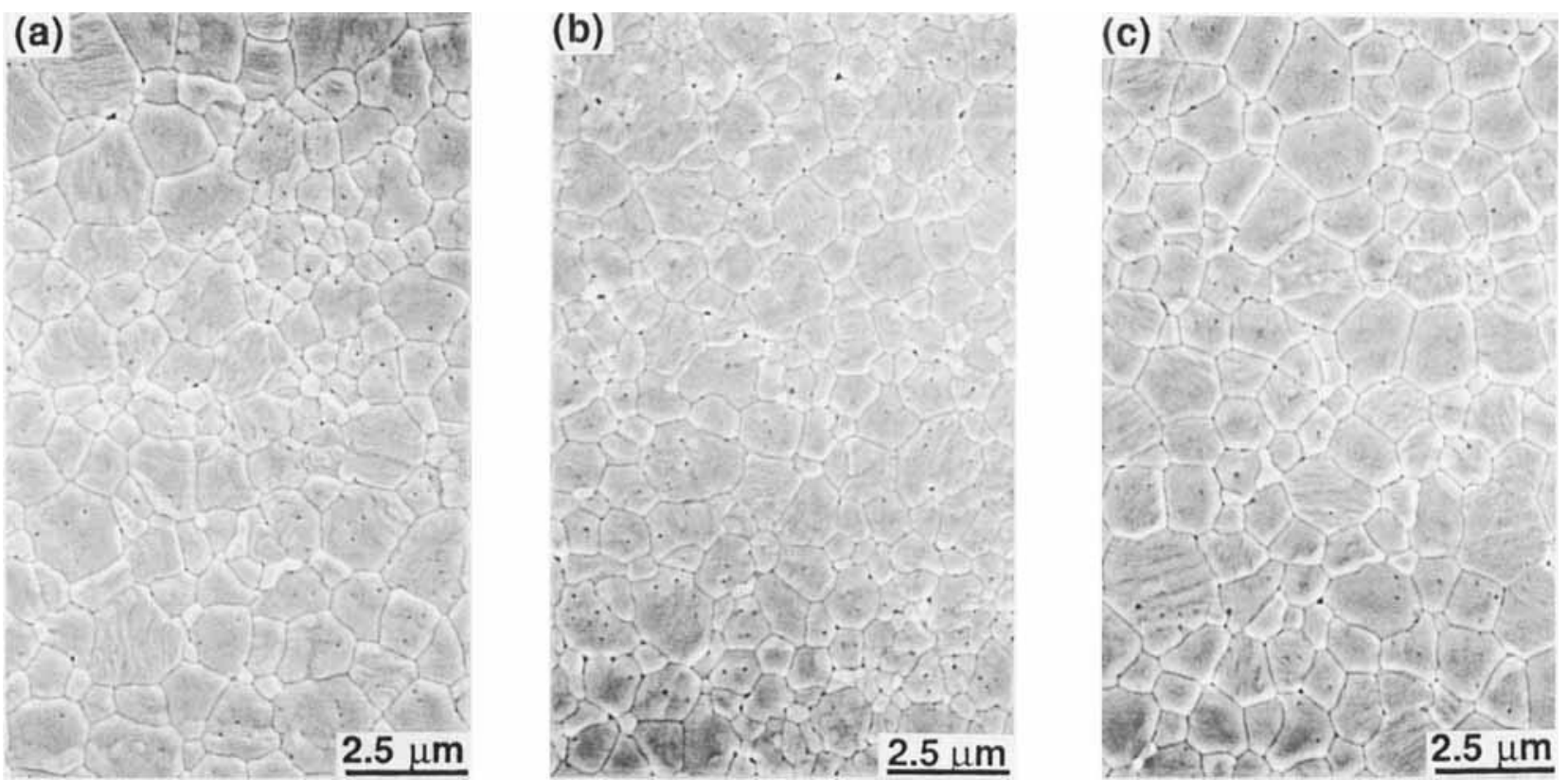

Fig. 6. Microstructures sintered at $1320^{\circ} \mathrm{C}$ for 6 min using Ce-HMT powders calcined at (a) $200^{\circ}$, (b) $450^{\circ}$, and (c) $850^{\circ} \mathrm{C}$, all for $1.5 \mathrm{~h}$.

surprisingly, two of the specimens from finer powders with similar green density have almost identical sintering behaviors. Yet the value of green density is again seen to have no effect on final density at the highest temperature. Significant shrinkage generally occurs above $950^{\circ} \mathrm{C}$ and reaches a maximum at around $1250^{\circ} \mathrm{C}$, although some shrinkage has already appeared above $500^{\circ} \mathrm{C}$ with the finer powders.

\section{Discussion}

\section{(1) Chemistry of the Ce-HMT Method}

According to the literature, ${ }^{9.10}$ hexamethylenetetramine possesses a unique characteristic of hydrolyzing quite slowly to produce formaldehyde and ammonia under acidic circumstances. This reaction and the subsequent hydrolysis of ammonia are expressed as

$$
\begin{aligned}
& \mathrm{C}_{6} \mathrm{H}_{12} \mathrm{~N}_{4}+6 \mathrm{H}_{2} \mathrm{O}=6 \mathrm{H}_{2} \mathrm{CO}+4 \mathrm{NH}_{3} \\
& \mathrm{NH}_{3}+\mathrm{H}_{2} \mathrm{O}=\mathrm{NH}_{4} \mathrm{OH}
\end{aligned}
$$

The hydrolysis can be controlled by adjusting $\mathrm{pH}$ and temperature. A lower $\mathrm{pH}$ or a higher temperature favors the hydrolysis.

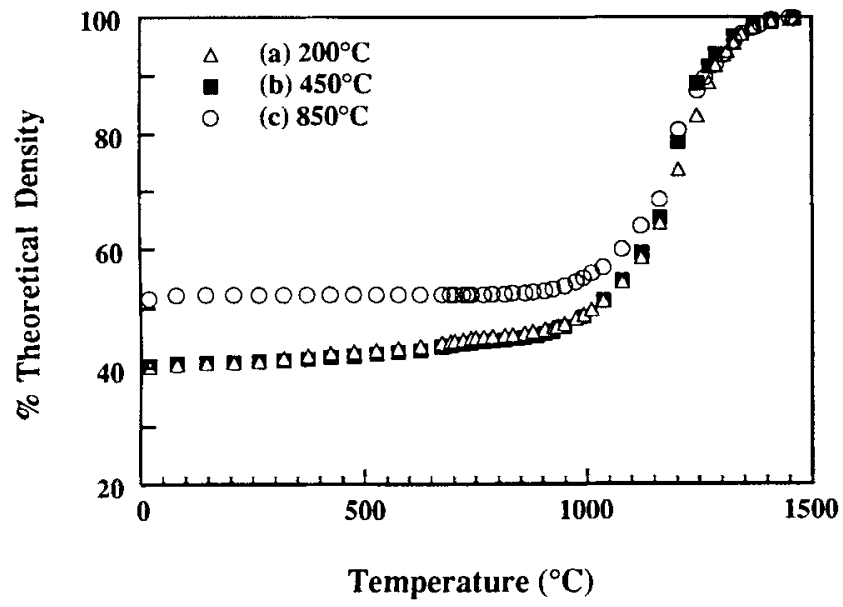

Fig. 7. Sintering curves of powders calcined at (a) $200^{\circ}$, (b) $450^{\circ}$, and (c) $850^{\circ} \mathrm{C}$.
Based on this knowledge, we suggest that the nucleation of the precipitates is achieved during room-temperature aging when the low $\mathrm{pH}$ favors hydrolysis which proceeds to attain the large critical supersaturation necessary for low-temperature nucleation. Once nucleated, precipitates by initial growth quickly exhaust the hydroxyl ions which cannot be replenished rapidly at low temperature despite the favorable $\mathrm{pH}$. Subsequent growth of the precipitates becomes possible only by heating to an appropriate temperature that effects further hydrolysis. In our study, the second aging temperature was adjusted to about $70^{\circ} \mathrm{C}$, and at a $\mathrm{pH}$ value of 6.4 , to provide sufficient but still slow hydrolysis to feed precipitate growth. In this way, very fine powders of a relatively narrow size distribution could be obtained with a high yield.

From the $\mathrm{X}$-ray diffraction data shown in Fig. 2, it is clear that the wet precipitate was already $\mathrm{CeO}_{2}$. Since the starting cerium salt is $\mathrm{Ce}\left(\mathrm{NO}_{3}\right)_{3}$, it requires the oxidation of $\mathrm{Ce}^{3+}$ to $\mathrm{Ce}^{4+}$ in the solution. In this system, there are two possible causes for this oxidation. First, according to the Lewis definitions of acids and bases, $\mathrm{Ce}^{3+}$ is a Lewis base and $\mathrm{Ce}^{4+}$ is a Lewis acid. Basic solution, therefore, favors $\mathrm{Ce}^{4+}$ compared with $\mathrm{Ce}^{3+}$. This is made possible by the hydrolysis of hexamethylenetetramine. (A similar situation is also encountered in the $\mathrm{Ce}-\mathrm{NH}_{4} \mathrm{OH}$ method where $\mathrm{CeO}_{2}$ was likewise found.) Second, among organic compounds, hexamethylenetetramine is an oxidation reagent itself (e.g., in the oxidation reaction of benzylic halides $\left.{ }^{9}\right)$. To differentiate between these two mechanisms, we have also attempted another experiment in which the $\mathrm{pH}$ value after HMT addition was readjusted to return to 4.5. The resultant powder from this process was still found to be $\mathrm{CeO}_{2}$. Thus, in the $\mathrm{Ce}-\mathrm{HMT}$ method, HMT must have played a more important role in $\mathrm{Ce}^{3+}$ oxidation.

Because of their lower basicity and higher charge, $\mathrm{Ce}^{4+}$ ions usually undergo strong hydration. The hydrated $\mathrm{Ce}^{4+}$ ions can form complexes with $\mathrm{H}_{2} \mathrm{O}$ molecules or $\mathrm{OH}^{-}$ions, in the form of $\mathrm{Ce}\left(\mathrm{H}_{2} \mathrm{O}\right)_{r}(\mathrm{OH})_{v}^{(4+y)+}$, where $x+y$ is the coordination number of $\mathrm{Ce}^{4+}$. Further polymerization of this hydroxide is also likely, and both can serve as precursors for the final oxide. Furthermore, in aqueous solution, $\mathrm{H}_{2} \mathrm{O}$ and $\mathrm{H}_{2} \mathrm{CO}$ as polar molecules tend to take protons away from the hydroxide, as represented below

$$
\mathrm{Ce}\left(\mathrm{H}_{2} \mathrm{O}\right)_{x}(\mathrm{OH})^{(4-y)+}+\mathrm{H}_{2} \mathrm{O} \rightarrow \mathrm{CeO}_{2} \cdot n\left(\mathrm{H}_{2} \mathrm{O}\right)+\mathrm{H}_{3} \mathrm{O}^{+}
$$


Thus, $\mathrm{CeO}$, forms even at a low temperature in the solution. Evidence for the release of $\mathrm{H}^{+}$ions in Eq. (3) is already seen in Fig. 1, which shows that the $\mathrm{pH}$ value of the solution decreases in both aging stages.

The color variation of the solution during reaction as described in Section III(1) provides additional information for the above oxidation/hydration process. We note that $\mathrm{CeO}_{2}$ powders typically have a light yellow tint. On the other hand, hydrated $\mathrm{CeO}_{2} \cdot n\left(\mathrm{H}_{2} \mathrm{O}\right)$ or $\mathrm{Ce}\left(\mathrm{H}_{2} \mathrm{O}\right)_{x}(\mathrm{OH})_{v}{ }^{(4-y)+}$ salt apparently has a ligand field that absorbs light differently to give it a pinkish-purple color. Such a color has appeared at the very beginning of the precipitation reaction, e.g., during roomtemperature aging, and remained essentially unchanged, only becoming more intense as the reaction is driven into completion. Thus, the valence state of the cation, $\mathrm{Ce}$ (IV) as we believe, must also remain the same throughout the above process. Final drying affects only dehydration and not valence, giving a light yellow product which is already $\mathrm{CeO}_{2}$.

\section{(2) Chemistry of the $\mathrm{Ce}-\mathrm{NH}_{4} \mathrm{OH}$ and $\mathrm{Ce}-\mathrm{Urea}$ Methods}

In the $\mathrm{Ce}-\mathrm{NH}_{4} \mathrm{OH}$ method, the precipitate is also $\mathrm{CeO}_{2}$ after vacuum drying at room temperature. This is evident from Fig. 2(a). Thus, once again it involves $\mathrm{Ce}^{3+} / \mathrm{Ce}^{4+}$ transfer. This may be due to the addition of a large amount of $\mathrm{NH}_{4} \mathrm{OH}$, which increases the $\mathrm{pH}$ value from 4.4 to 10 . According to the emf data $^{14}$

$$
\begin{aligned}
\mathrm{Ce}^{3+}+\mathrm{H}_{2} \mathrm{O} & \Leftrightarrow \mathrm{Ce}(\mathrm{OH})^{3+}+\mathrm{H}^{+}+\mathrm{e} \\
\left(E_{\mathrm{ox}}^{\circ}\right. & =-1.70 \mathrm{~V})
\end{aligned}
$$

Thus, an increase of $0.36 \mathrm{~V}$ in emf can be realized from the above $\mathrm{pH}$ change. The very high $\mathrm{pH}$ value also favors the hydrolysis of the relatively large $\mathrm{Ce}^{3+}$ ion. These factors combined are apparently sufficient in effecting $\mathrm{Ce}^{3+}$ oxidation. The subsequent precipitation reaction for $\mathrm{CeO}_{2}$ is similar to that in the Ce-HMT method.

In the $\mathrm{Ce}$-urea method, the precipitate is $\mathrm{Ce}_{2} \mathrm{O}\left(\mathrm{CO}_{3}\right)_{2} \cdot \mathrm{H}_{2} \mathrm{O}$ rather than $\mathrm{CeO}_{2}$ which agrees with the observation reported by Matijevic and $\mathrm{Hsu} .{ }^{7}$ In this case, urea decomposes according to the following reaction:

$$
\left(\mathrm{NH}_{2}\right)_{2} \mathrm{CO} \rightarrow \mathrm{NH}_{3}+\mathrm{HNCO}
$$

Then, by further hydrolysis of $\mathrm{HNCO}, \mathrm{CO}_{3}{ }^{2-}$ ions form to provide the source of carbonate precipitation. Unlike other trivalent lanthanide ions $\left(\mathrm{R}=\mathrm{Gd}^{3+}, \mathrm{Eu}^{3+}, \mathrm{Tb}^{3+}\right.$, and $\left.\mathrm{Sm}^{3+}\right), \mathrm{Ce}^{3+}$ does not hydrolyze to $\mathrm{ROH}^{2+}$ before forming its carbonate. Instead, direct precipitation reaction occurs via

$$
\begin{aligned}
2 \mathrm{Ce}\left(\mathrm{H}_{2} \mathrm{O}\right)_{n}{ }^{3+}+ & 3 \mathrm{CO}_{3}{ }^{2-} \rightarrow \mathrm{Ce}_{2} \mathrm{O}\left(\mathrm{CO}_{3}\right)_{2} \mathrm{H}_{2} \mathrm{O} \\
+ & \mathrm{CO}_{2}+(2 n-1) \mathrm{H}_{2} \mathrm{O}
\end{aligned}
$$

as suggested by Matijevic et al., ${ }^{7}$ which is an entirely different path from that taken by $\mathrm{Ce}^{4+}$ ions in the Ce-HMT method.

It seems plausible that the reason which causes this difference between the $\mathrm{Ce}-\mathrm{HMT}$ method and the $\mathrm{Ce}-$ urea method lies in the solution chemistry. In the Ce-HMT method, the major ligands in the solution are $\mathrm{OH}^{-}$ions. In the $\mathrm{Ce}$-urea method, however, the major ligands are $\mathrm{OH}^{-}$ions and $\mathrm{CO}_{3}{ }^{2-}$ ions. The formation of $\mathrm{Ce}_{2} \mathrm{O}\left(\mathrm{CO}_{3}\right)_{2}$ rather than $\mathrm{CeO}_{2}$ in the $\mathrm{Ce}-$ urea method is the result of the competition between $\mathrm{OH}^{-}$and $\mathrm{CO}_{3}^{2-}$. Other subtle effects of ionic size may also be significant since, in the urea method, the $\mathrm{Ce}$ (III) precipitate is crystalline $\mathrm{Ce}_{2} \mathrm{O}\left(\mathrm{CO}_{3}\right)_{2}$ while smaller trivalent rare earth precipitates are amorphous hydroxyl carbonates.

\section{(3) Sinterability of Powders}

The process we used has a high yield, between $70 \%$ and $75 \%$. At the typical cation concentration, $3.75 \times 10^{-2} \mathrm{M}$, at least $4.68 \mathrm{~g}$ of $\mathrm{CeO}_{2}$ powders can be obtained from $1 \mathrm{~L}$ of solution. This is a more favorable yield than the one reported by Hsu et $\mathrm{al}^{.}{ }^{8}$ and Matijevic et al. ${ }^{7}$ where cation concentrations ranging from $10^{-3}$ to $10{ }^{4} M$ were used.
The sinterability of the powders produced by the Ce-HMT method is obviously excellent. They can be sintered to full density at temperatures below $1300^{\circ} \mathrm{C}$. Most reports on pure $\mathrm{CeO}_{2}$ have utilized a sintering temperature above $1500^{\circ} \mathrm{C}$. Moreover, none of them, to our knowledge, was able to achieve a high density above say $97 \%{ }^{15.16}$ The excellent sinterability is insensitive to particle/crystallite size and can be maintained after coarsening at higher calcination temperature, say $850^{\circ} \mathrm{C}$, which increases the crystallite size to about $600 \AA$ and reduces the surface area to about $10 \mathrm{~m}^{2} / \mathrm{g}$. The coarser powders, which have a higher tapped and green density, are clearly preferred from a practical point of view, which favors a smaller sintering shrinkage and easier handling. In these respects they are comparable to the best industrial powders of high melting point ceramics available today, such as alumina and yttria-stabilized tetragonal zirconia. $^{17}$

It is also interesting to point out that the high sinterability obtained here does not require powders which are monosized and spherical. In contrast, for the case of $\mathrm{Y}_{2} \mathrm{O}_{3}$, Sordelet et al. ${ }^{3}$ used monosized spherical powders but could not obtain sintered density above $99 \%$ at $1700^{\circ} \mathrm{C}$. They attributed this deficiency to the agglomeration and fault generated during dry handling of the powders. This is not consistent with our experience, since our pressed pellets of rather low green densities apparently have no difficulty reaching full density. In fact, despite many reports ${ }^{17.19}$ that emphasize the importance of green density and good packing, which argues for direct shaping from the colloidal state, we have found that, with powders of inherently better sinterability, sintering can be very forgiving to the handling and green packing methods.

The apparent contradiction of our observations to these generally expressed opinions in the literature can be reconciled by the following reasoning. The indifference of sintering to the powder calcination temperature and hence, the particle size, can be understood from inspection of Fig. 7. Since the sintering temperature is always far above the highest calcination temperature, and substantial shrinkage already takes place at lower temperatures, it is obvious that powders must have coarsened substantially during heating. Thus, the effective powder size at the sintering temperature is always much larger than the starting powder size, rendering the latter mostly irrelevant. On the other hand, we believe that a key attribute of our powders that is responsible for their superior sinterability is related to the direct formation of $\mathrm{CeO}_{2}$ from precipitation. Absent from any chemical reactions and bonding changes that usually take place in calcination, the tendency for forming solid bridges between our powders is greatly reduced even during heat treatment. Thus, the powders are soft and unagglomerated, giving rise to excellent sinterability regardless of the handling and heat treatment techniques employed.

\section{Conclusions}

(1) Highly sinterable $\mathrm{CeO}_{2}$ powders have been prepared using a high-yield homogeneous precipitation method utilizing hexamethylenetetramine and trivalent cerium salt.

(2) Oxidation of $\mathrm{Ce}^{3+}$ takes place in the solution before hydrolysis, which is followed by crystallization of $\mathrm{CeO}_{2}$. $n\left(\mathrm{H}_{2} \mathrm{O}\right)$.

(3) The dried $\mathrm{CeO}_{2}$ powders can be easily sintered, with or without calcination, to full density at temperatures below $1300^{\circ} \mathrm{C}$ using green bodies formed by dry-pressing and wet bag techniques.

(4) Sinterability is found to be insensitive to particle size green density, and forming method. Direct formation of $\mathrm{CeO}_{2}$ from precipitation is believed to reduce the chance of forming solid bridges between particles during calcination which hinders sinterability. 


\section{References}

'W. H. Rhodes, E. A. Trickett, and D. J. Sordelet, "Key Powder Characteristics in Sintered Optical Ceramics"; pp. 677-90 in Ceramic Transactions, Vol. 12, Ceramic Powder Science III. Edited by G. L. Messing, S. Hirano, and H. Hausner. American Ceramic Society, Westerville, OH, 1990.

${ }^{2}$ D. J. Sordelet and M. Akinc, "Sintering of Monosized, Spherical $\mathrm{Y}_{2} \mathrm{O}_{2}$ Powders"; pp. 332-44 in Ceramic Transactions, Vol. 7. Sintering of Advanced Ceramirs. Edited by C. A. Handwerker. J. E. Blendell, and W. Kaysser. American Ceramic Society, Westerville, $\mathrm{OH}, 1988$.

${ }^{3} \mathrm{D}$. J. Sordelet and M. Akinc, "Sintering of Monosized Spherical Yttria Powders," J. Am. Ceram. Soc., $71[12] 1148-53$ (1988).

${ }^{4} \mathrm{H}$. Willard and N. Tang, "A Study of the Precipitation of Aluminum Basic Sulfate by Urea," J. Am. Chem. Soc., 59, 1190-96 (1937).

D. Sordelet and M. Akine, "Preparation of Spherical, Monosized $\mathrm{Y}_{2} \mathrm{O}_{2}$ Precursor Particles," J. Colloid Interface Sci., 122, 47-59 (1988).

${ }^{6}$ B. Aiken, W. P. Hsu, and E. Matijevic, "Preparation and Properties of Monodispersed Colloidal Particles of Lanthanide Compounds: III. Yttrium(III) and Mixed Yttrium(III)/Cerium(III) Systems," J. Am. Ceram. Soc., 71 [10] 845-53 (1988).

${ }^{7} \mathrm{E}$. Matijevic and W. P. Hsu, "Preparation and Properties of Monodispersed Colloidal Particles of Lanthanide Compounds, I. Gadolinium, Europium. Terbium, Samarium, and Cerium(III)," J. Colloid Interface Sci., 118, 506-23 (1987)

${ }^{8}$ W. P. Hsu, L. Ronnquist, and E. Matijevic, "Preparation and Properties of Monodispersed Colloidat Particles of Lanthanide Compounds II. Cerium(IV)," Langmuir, 4, 31-37 (1988).
"N. Blazevic and D. Kolbah. "Hexamethylenetetramine-A Versatile Reagent in Organic Synthesis," Synthesis, 16I-76 (1979).

"IJ. M. Dreyfors, S. B. Jones, and Y. Sayed, "Hexamethylenetetramine, A Review," Am. Ind. Hyg. Assoc. J., 50 [1!] 579-85 (1989).

"K. Fujita and I. Kayama, "Synthesis of Zinc Oxide by the Homogenevus Precipitation Method," Yogyo Kyokaishi, 88 [10] 619-23 (1980).

"K. Fujita, K. Murata, T. Nakazawa, and I. Kayama, "Crystal Shapes of Zine Oxide Prepared by the Homogeneous Precipitation Method." Yogyo Kyokaishi. $92[4] 227-30(1984)$

${ }^{1 " Y}$. Sakka, K. Halada, and E. Ozawa, "Synthesis of ZnO Particles by the Homogeneous Precipitation Method"; pp. 31-38 in Ceramic Transactions, Vol. 1. Ceramic Powder Science II. Edited by G. L. Messing, S. Hirano, and H. Hausner. American Ceramic Society, Westerville, OH, 1988.

${ }^{14}$ R. C. Weast, M. J. Astle, and W. H. Beyer (Eds.), CRC Handbook of Chemistry and Physics. CRC Press, Boca Raton, FL, 1984.

${ }^{15}$ D. A. Wang, D. S. Park, J. Griffith, and A. S. Nowick, "Oxygen-lon Conductivity and Defect Interactions in Yttria-Doped Ceria." Solid State Ionics, 2, 95-105 (1981).

${ }^{1 h}$ A. L. Dragon and L. P. Domingues, "Preparation of High-Density CeriaYttria Ceramics,"J. Am. Ceram. Soc., 65 [5] 253-59 (1982).

${ }^{17}$ W. H. Rhodes, "Agglomerate and Particle Size Effects on Sintering YttriaStabilized Zirconia," J. Am. Ceram. Soc., 64 [1] 19-22 (1981).

${ }^{18} \mathrm{E}$. A. Barringer and H. K. Bowen, "Formation, Packing and Sintering of Monodispersed $\mathrm{TiO}_{2}$ Powders," J. Am. Ceram. Soc., 65 [12] C-199-C-20] (1982)

"T. S. Ych and M. D. Sacks, "Effect of Particle Size Distribution on the Sintering of Alumina," J. Am. Ceram. Soc., 71 [12] 484-87 (1988). 